\title{
In Vitro Synergism of Penicillin and Ceftriaxone against Enterococcus faecalis
}

\author{
Lara Thieme $^{1,2, *}$, Simon Briggs $^{3}$, Eamon Duffy $^{3} \mathbb{D}$, Oliwia Makarewicz ${ }^{1}$ and Mathias W. Pletz ${ }^{1}$ (D) \\ 1 Institute for Infectious Diseases and Infection Control, Jena University Hospital, Friedrich Schiller University, \\ 07747 Jena, Germany; oliwia.makarewicz@med.uni-jena.de (O.M.); mathias.pletz@med.uni-jena.de (M.W.P.) \\ 2 Leibniz Center for Photonics in Infection Research, Jena University Hospital, Friedrich Schiller University, \\ 07747 Jena, Germany \\ 3 Infectious Disease Unit, Auckland City Hospital, Auckland 1023, New Zealand; SBriggs@adhb.govt.nz (S.B.); \\ EamonD@adhb.govt.nz (E.D.) \\ * Correspondence: Lara.Thieme@med.uni-jena.de
}

Citation: Thieme, L.; Briggs, S.;

Duffy, E.; Makarewicz, O.; Pletz, M.W. In Vitro Synergism of Penicillin and Ceftriaxone against Enterococcus faecalis. Microorganisms 2021, 9, 2150. https://doi.org/10.3390/ microorganisms 9102150

Academic Editor: Suresh Joshi

Received: 23 August 2021

Accepted: 10 October 2021

Published: 14 October 2021

Publisher's Note: MDPI stays neutral with regard to jurisdictional claims in published maps and institutional affiliations.

Copyright: (c) 2021 by the authors. Licensee MDPI, Basel, Switzerland. This article is an open access article distributed under the terms and conditions of the Creative Commons Attribution (CC BY) license (https:// creativecommons.org/licenses/by/ $4.0 /)$.

\begin{abstract}
Enterococcus faecalis infective endocarditis is commonly treated with intravenous ampicillin/ceftriaxone combination therapy. Ampicillin, however, is unsuitable for outpatient parenteral antibiotic therapy (OPAT) regimens due to its instability in $24 \mathrm{~h}$ continuous infusors, and has been successfully replaced by benzylpenicillin used together with ceftriaxone in a few small case series. Since in vitro synergy data of penicillin/ceftriaxone against E. faecalis are still lacking, checkerboard assays were performed for 28 clinical E. faecalis isolates and one laboratory standard strain. Synergistic effects (both lowest and median FICI) were observed for penicillin/ceftriaxone in 15/29 isolates, while ampicillin/ceftriaxone exhibited synergism in 22/29 isolates. For isolates with ceftriaxone MICs $\leq 256 \mathrm{mg} / \mathrm{L}$, the addition of free ceftriaxone trough concentrations to penicillin or ampicillin resulted in comparable synergistic effects for both combinations. In contrast, for isolates with ceftriaxone MICs $\geq 512 \mathrm{mg} / \mathrm{L}$ free ceftriaxone trough concentrations were only sufficient to exhibit synergistic effects in combination with ampicillin, but not penicillin. This study suggests that benzylpenicillin/ceftriaxone would be expected to be suitable for the OPAT treatment of enterococcal endocarditis for $E$. faecalis isolates with ceftriaxone MICs $\leq 256 \mathrm{mg} / \mathrm{L}$. However, combination therapy would be expected to provide no advantage over benzylpenicillin monotherapy for isolates with ceftriaxone MICs $\geq 512 \mathrm{mg} / \mathrm{L}$. Further investigation is required to analyse the relationship between ceftriaxone susceptibility and penicillin/ceftriaxone synergy, especially for isolates with ceftriaxone MICs of 64 to $512 \mathrm{mg} / \mathrm{L}$.
\end{abstract}

Keywords: E. faecalis endocarditis; synergism; OPAT; penicillin/ceftriaxone; ampicillin/ceftriaxone; checkerboard

\section{Introduction}

Enterococcus faecalis is an increasingly common cause of infective endocarditis (IE) and should be treated with prolonged synergistic, bactericidal antibiotic combination therapy [1,2]. Contemporary treatment guidelines recommend the use of intravenous (IV) ampicillin, amoxicillin, or benzylpenicillin combined with IV gentamicin for gentamicin susceptible isolates, or IV ampicillin combined with IV ceftriaxone for both high-level aminoglycoside-resistant (HLAR) and non-HLAR isolates [2,3]. Ceftriaxone is a more attractive synergy antibiotic than gentamicin, since it causes significantly fewer adverse effects $[1,4]$.

Although a previous guideline for the Outpatient Parenteral Antibiotic Therapy (OPAT) treatment of IE was restrictive [5], a recent prospective cohort study has shown that the OPAT treatment of a broader range of patients with IE provided excellent results [6]. The abovementioned guideline-recommended regimens for the treatment of E. faecalis IE (EFIE) may be challenging to administer via an OPAT service due to the multiple doses 
required per day. The administration of the treatment by community nurses is often limited to once or twice daily injections or changing a $24 \mathrm{~h}$ elastomeric continuous infusor. While ampicillin/ceftriaxone has been proposed as an OPAT regimen for EFIE utilising either elastomeric continuous infusors or programmable pumps for the delivery of ampicillin [7], the literature shows conflicting results regarding the stability of ampicillin in elastomeric continuous infusors [8-11]. While ampicillin, which cannot be applied orally for reasons of bioavailability, could theoretically be replaced by orally administered amoxicillin, the clinical evidence supporting oral antibiotic regimens for treating EFIE is scarce. The use of oral antibiotics as part of the treatment of endocarditis has only been assessed in one trial [12] that enrolled a tightly defined group of patients with left-sided endocarditis who were transitioned to oral regimens. The patients with EFIE were treated with a variety of oral antibiotic combinations, the most common of which were amoxicillin /moxifloxacin, amoxicillin/linezolid, and amoxicillin/rifampicin. Oral amoxicillin/IV ceftriaxone has not been tested in a trial situation, as far as we are aware, and should therefore only be administered as part of a very carefully designed trial.

IV benzylpenicillin has been used as an alternative to IV ampicillin/amoxicillin for the treatment of EFIE, since benzylpenicillin is more stable in elastomeric continuous infusors and therefore better suited for OPAT regimens. The use of intravenous benzylpenicillin/ceftriaxone for the OPAT-guided treatment of E. faecalis endocarditis is common in New Zealand and also occurs in Australia and America. Benzylpenicillin has been successfully combined with ceftriaxone for the OPAT treatment of enterococcal endocarditis in a few small clinical case series [13-15], but in vitro synergy data supporting the use of benzylpenicillin with ceftriaxone for OPAT regimens are still lacking.

Here, we report the checkerboard synergy analysis of penicillin/ceftriaxone and ampicillin/ceftriaxone in 28 clinical E. faecalis isolates and one laboratory standard strain, allowing for a comparison of both combinations at concentrations achieved by OPAT dosage regimens.

\section{Materials and Methods}

\subsection{Enterococcal Strains and Antibiotics}

Clinical E. faecalis isolates were obtained from blood cultures from, or the heart valves of, patients with enterococcal infection at various foci, including eight patients with infective endocarditis (Table 1). The antibiotic-susceptibility data for all clinical isolates are depicted in Table S1. All patients were admitted to Jena University Hospital, Germany, in 2015. E. faecalis ATCC 29,212 served as a reference strain. Bacterial liquid cultures were prepared in Todd Hewitt broth (Karl Roth, Karlsruhe, Germany). Test solutions of ampicillin (AMP) (Karl Roth, Karlsruhe, Germany), ceftriaxone (CRO) (TCI Europe, Zwijndrecht, Belgium), and benzylpenicillin (PEN) (InfectoPharm, Heppenheim, Germany) were prepared immediately before use.

Table 1. Susceptibility (MIC) and synergy (FICI) results for penicillin/ceftriaxone versus ampicillin/ceftriaxone in the patient cohort.

\begin{tabular}{|c|c|c|c|c|c|c|c|c|}
\hline Isolate $^{a}$ & $\begin{array}{c}\text { Clinical } \\
\text { Background }\end{array}$ & Gender & $\begin{array}{c}\text { Age } \\
\text { (Years) }\end{array}$ & $\begin{array}{c}\text { MIC CRO } \\
(\mathrm{mg} / \mathrm{L})\end{array}$ & $\begin{array}{c}\text { MIC PEN } \\
(\mathrm{mg} / \mathrm{L})\end{array}$ & $\begin{array}{c}\text { MIC AMP } \\
(\mathrm{mg} / \mathrm{L})\end{array}$ & $\begin{array}{l}\text { FICI }^{d} \text { of } \\
\text { PEN/CRO }\end{array}$ & $\begin{array}{c}\text { FICI of } \\
\text { AMP/CRO }\end{array}$ \\
\hline 5187 & urosepsis & male & 79 & $1-2^{c}$ & 1 & 1 & $0.75(1.13)$ & $0.63(0.88)$ \\
\hline 245 & endocarditis & male & 76 & $2^{c}$ & 1 & 0.5 & $0.75(1.03)$ & $0.63(0.88)$ \\
\hline 26,786 & endocarditis & male & 67 & 2 & 1 & 0.25 & $0.56(\mathbf{0 . 7 5 )}$ & $0.74(1.05)$ \\
\hline 404 & endocarditis & female & 78 & 4 & 0.5 & 0.25 & $0.75(\mathbf{0 . 7 5 )}$ & $0.49(0.68)$ \\
\hline
\end{tabular}


Table 1. Cont.

\begin{tabular}{|c|c|c|c|c|c|c|c|c|}
\hline Isolate $^{a}$ & $\begin{array}{c}\text { Clinical } \\
\text { Background }\end{array}$ & Gender & $\begin{array}{c}\text { Age } \\
\text { (Years) }\end{array}$ & $\begin{array}{c}\text { MIC CRO } \\
(\mathrm{mg} / \mathrm{L})\end{array}$ & $\begin{array}{c}\text { MIC PEN } \\
(\mathrm{mg} / \mathrm{L})\end{array}$ & $\begin{array}{c}\text { MIC AMP } \\
(\mathrm{mg} / \mathrm{L})\end{array}$ & $\begin{array}{l}\text { FICI }^{\mathrm{d}} \text { of } \\
\text { PEN/CRO }\end{array}$ & $\begin{array}{c}\text { FICI of } \\
\text { AMP/CRO }\end{array}$ \\
\hline ATCC & / & / & / & 4 & 1 & 1 & $0.75(\mathbf{0 . 7 5})$ & $0.50(0.69)$ \\
\hline 6747 & $\begin{array}{l}\text { biliary tract } \\
\text { infection }\end{array}$ & male & 81 & $4^{c}$ & 1 & 1 & $0.75(\mathbf{0 . 7 5 )}$ & $0.50(0.63)$ \\
\hline 11,223 & endocarditis & female & 65 & 8 & 2 & 0.5 & $0.38(0.56)$ & $0.31(0.50)$ \\
\hline 22,424 & endocarditis & male & 68 & 8 & 1 & 0.5 & $0.25(0.56)$ & $0.37(0.47)$ \\
\hline 8669 & OI & male & 80 & $8^{c}$ & 1 & 1 & $0.63(\mathbf{0 . 7 5 )}$ & $0.25(0.38)$ \\
\hline 9367 & $\begin{array}{c}\text { recurrent } \\
\text { bacteraemia }\end{array}$ & female & 85 & $8^{c}$ & 2 & 2 & $0.50(0.63)$ & $0.38(0.63)$ \\
\hline 1653 & urosepsis & female & 87 & $8^{c}$ & 2 & 1 & $0.38(0.63)$ & $0.38(0.56)$ \\
\hline 848 & OI & male & 60 & 8 & 2 & 1 & $0.38(0.56)$ & $0.31(0.47)$ \\
\hline 5597 & OI & female & 55 & $8-16^{c}$ & 2 & 1 & $0.31(0.52)$ & $0.50(0.63)$ \\
\hline 10,485 & endocarditis & male & 74 & 16 & 1 & 0.5 & $\mathbf{0 . 3 8}(0.81)$ & $0.24(0.53)$ \\
\hline 6886 & $\begin{array}{l}\text { wound } \\
\text { infection }\end{array}$ & female & 68 & $16^{\mathrm{c}}$ & 1 & 2 & $0.63(\mathbf{0 . 7 5 )}$ & $0.31(0.52)$ \\
\hline 281 & sepsis & female & 79 & $16^{\mathrm{c}}$ & 1 & 1 & $0.50(0.63)$ & $0.31(0.38)$ \\
\hline 67,230 & endocarditis & male & 39 & 16 & 2 & 1 & $0.38(0.47)$ & $0.25(0.45)$ \\
\hline 2164 & OI & female & 78 & $16^{c}$ & 2 & 2 & $0.25(0.56)$ & $0.38(0.63)$ \\
\hline 4497 & urosepsis & female & 67 & $32^{c}$ & 2 & 1 & $0.31(0.45)$ & $0.38(0.56)$ \\
\hline 10,021 & urosepsis & female & 42 & 32 & 1 & 0.5 & $0.56(1.01)$ & $0.15(0.34)$ \\
\hline 13,703 & bacteraemia & male & 54 & 256 & 2 & 1 & $0.16(0.27)$ & $0.16(0.37)$ \\
\hline 7914 & OI & male & 54 & 256 & 1 & 0.25 & $0.25(0.38)$ & $0.26(0.37)$ \\
\hline 905 & endocarditis & male & 75 & 512 & 2 & 1 & $0.31(0.52)$ & $0.27(0.44)$ \\
\hline 6037 & urosepsis & male & 86 & $1024^{c}$ & 1 & 1 & $0.27(0.51)$ & $0.12(0.25)$ \\
\hline 7183 & urosepsis & male & 76 & 1024 & 2 & 1 & $0.31(0.55)$ & $0.38(0.52)$ \\
\hline 3043 & OI & female & 74 & $>1024$ & 2 & 0.5 & N. A. & N. A. \\
\hline 8653 & OI & male & 56 & $>1024$ & 2 & 1 & N. A. & N. A. \\
\hline 3062 & urosepsis & male & 77 & $>1024$ & 4 & 1 & N. A. & N. A. \\
\hline 9190 & $\begin{array}{l}\text { wound } \\
\text { infection }\end{array}$ & female & 59 & $>1024$ & 4 & 1 & N. A. & N. A. \\
\hline
\end{tabular}

a E. faecalis isolates were obtained from the Institute of Medical Microbiology in Jena, Germany. All clinical isolates originated from blood cultures except for 67230 and 245 , which were sampled by swabs from infected mitral valves. / = N.A. to the laboratory standard strain ATCC $29,212 .{ }^{b}$ OI = opportunistic infection. ${ }^{c}$ In some isolates, ceftriaxone treatment led to trailing MIC endpoints, with wells showing the same level of turbidity observed in the growth control; followed by wells with less, but still visible, turbidity; and eventually wells with pinpoint growth (small aggregates). According to the EUCAST reading guide for broth microdilution [16], pinpoint growth was disregarded and recorded as the MIC. ${ }^{\mathrm{d}}$ FICI values are given as the lowest FICI with the median FICI in parentheses. Synergistic FICI values (lowest FICI $\leq 0.5$ and median FICI $\leq 0.8$ ) are indicated in bold. N.A. $=$ not determined due to MIC $>1024 \mathrm{mg} / \mathrm{L}$.

\subsection{Synergism Testing by Checkerboard Assays}

Checkerboard assays for penicillin/ceftriaxone were performed as described previously [17], with 11 and 7 serial 2-fold dilution steps for benzylpenicillin and ceftriaxone, respectively. The benzylpenicillin concentrations tested were chosen to cover the penicillin breakpoint range. The ceftriaxone concentrations tested included those that approximate the range of estimated or measured mean free plasma ceftriaxone trough concentrations expected to be achieved with OPAT ceftriaxone-dosing regimens of $2 \mathrm{~g}$ every $12 \mathrm{~h}, 4 \mathrm{~g}$ once daily, or $2 \mathrm{~g}$ once daily (4,1.5, and $1 \mathrm{mg} / \mathrm{L}$, respectively) [18-20], hereafter referred to as "free ceftriaxone trough concentrations". The checkerboard assays used for ampi- 
cillin/ceftriaxone were partly assessed in a previous study [21]; however, they were newly evaluated according to novel EUCAST guidelines [16] (see Table 1, footnote c), which has led to a change in MICs and fractional inhibitory concentrations indices (FICI) for 10 out of 21 previously tested isolates. Checkerboards for ampicillin/ceftriaxone were repeated for eight of these isolates to guarantee the reproducibility of previous results. Each checkerboard assay was performed in duplicate. The effects of the combined antibiotics were evaluated by calculating the FICI along the turbidity/non-turbidity interface using the following formula:

$\mathrm{FICI}_{\text {penicillin } / \text { ceftriaxone }}=\frac{\text { MIC penicillin }(\text { combination })}{\text { MIC penicillin }(\text { alone })}+\frac{\text { MIC ceftriaxone }(\text { combination })}{\text { MIC ceftriaxone }(\text { alone })}$.

Three different methods for interpreting the FICIs were used: (i) the lowest FICI value, with values $\leq 0.5$ indicating synergism and $0.5<\mathrm{FICI}<4$ indicating no interaction; (ii) the median FICI value, taking 0.8 as the synergy threshold; (iii) single, one-point FICIs at free ceftriaxone trough concentrations.

\subsection{Statistical Analysis}

The correlation of the MICs and FICIs was tested using the nonparametric Spearman's rank-correlation coefficient $\left(\mathrm{r}_{\mathrm{s}}\right)$ with a two-tailed CI of $95 \%$.

\section{Results}

Synergistic effects were observed for penicillin/ceftriaxone in 16 (lowest FICI method) and 21 (median FICI method) of the 29 tested E. faecalis strains (Table 1). Ampicillin/ceftriaxone synergised in 22 strains (both lowest and median FICI method) (Table 1). Ampicillin MICs $\left(\mathrm{MIC}_{\mathrm{AMP}}\right.$ ) ranged from 0.25 to $2 \mathrm{mg} / \mathrm{L}$, while penicillin MICs $\left(\mathrm{MIC}_{\mathrm{PEN}}\right.$ ) ranged from 0.5 to $4 \mathrm{mg} / \mathrm{L}$, the highest $\mathrm{MIC}_{\mathrm{PEN}}$ of $4 \mathrm{mg} / \mathrm{L}$ being below the CLSI susceptibility breakpoint of $8 \mathrm{mg} / \mathrm{L}$. Ceftriaxone MICs $\left(\mathrm{MIC}_{\mathrm{CRO}}\right)$ ranged from 1-2 to more than $1024 \mathrm{mg} / \mathrm{L}$. The $\mathrm{MIC}_{\mathrm{AMP}}$ showed no correlation with the $\mathrm{MIC}_{\mathrm{CRO}}$, but the MIC $\mathrm{CEN}_{\mathrm{PE}}$ exhibited a weak positive correlation with the $\mathrm{MIC}_{\mathrm{CRO}}\left(\mathrm{r}_{\mathrm{s}}=0.52, p=0.004\right)$. Both the $\mathrm{MIC}_{\mathrm{PEN}}$ and $\mathrm{MIC}_{\mathrm{CRO}}$ displayed a strong inverse correlation with the FICI values of penicillin/ceftriaxone ( $\mathrm{FICI}_{\mathrm{PEN} / \mathrm{CRO}}$ ) -i.e., the higher the $\mathrm{MIC}_{\mathrm{PEN}}$ or $\mathrm{MIC}_{\mathrm{CRO}}$, the lower the $\mathrm{FICI}_{\mathrm{PEN} / \mathrm{CRO}}\left(\mathrm{MIC}_{\mathrm{PEN}} \mathrm{r}_{\mathrm{s}}=-0.61, p=0.001 ; \mathrm{MIC}_{\mathrm{CRO}} \mathrm{r}_{\mathrm{s}}=-0.71, p<0.001\right)$. The MIC $\mathrm{CRO}$ inversely correlated with the $\mathrm{FICI}_{\mathrm{AMP} / \mathrm{CRO}}\left(\mathrm{r}_{\mathrm{s}}=-0.76, p<0.001\right)$, but the $\mathrm{MIC}_{\mathrm{AMP}}$ did not.

To analyse whether the synergistic effects determined by the lowest and median FICI methods were achieved at free ceftriaxone trough concentrations, the lowest sub-MIC ceftriaxone concentrations that resulted in a reduction in the $\mathrm{MIC}_{\mathrm{PEN}}$ or $\mathrm{MIC}_{\mathrm{AMP}}$ to one half, one quarter, and one eighth of the $\mathrm{MIC}_{\mathrm{PEN}}$ or $\mathrm{MIC}_{\mathrm{AMP}}$ are recorded in Table 2, together with the corresponding single, one-point FICIs. For 13 isolates (9367; 1653; 848; 5597; 6886; 67,230; $2164 ; 4497 ; 11,223 ; 22,424 ; 10,485 ; 13,703 ; 7914)$, synergy between penicillin/ceftriaxone occurred at free ceftriaxone trough concentrations, while for another 8 isolates $(5187 ; 245$; ATCC; $6747 ; 8669 ; 281 ; 26,786 ; 404)$, the addition of these free ceftriaxone trough concentrations resulted in a four-fold reduction in the $\mathrm{MIC}_{\mathrm{PEN}}$ but with FICIs above the synergy threshold of 0.5 . In contrast, ampicillin/ceftriaxone exhibited synergism in 23 isolates at free ceftriaxone trough concentrations. For the isolates with $\mathrm{MIC}_{\mathrm{CRO}} \geq 512 \mathrm{mg} / \mathrm{L}$, lower sub-MIC ceftriaxone concentrations were required in combination with ampicillin than in combination with penicillin to produce the same effect (Table 2). Here, the addition of free ceftriaxone trough concentrations to penicillin resulted in a reduction in the $\mathrm{MIC}_{\mathrm{PEN}}$ in one of seven isolates, whereas the addition to ampicillin reduced the MIC $\mathrm{AMP}_{\mathrm{A}}$ in six of seven isolates. 
Table 2. Lowest sub-MIC CRO concentrations resulting in two-, four-, and eight-fold reductions in the effective $\mathrm{MIC}_{\mathrm{PEN}}$ or $\mathrm{MIC}_{\mathrm{AMP}}$ and corresponding FICI values of the resulting concentration combinations.

\begin{tabular}{|c|c|c|c|c|c|c|c|c|c|c|c|c|c|}
\hline \multirow{3}{*}{ Isolate } & \multirow{3}{*}{$\begin{array}{l}\mathrm{MIC}_{\mathrm{CRO}} \\
\text { Alone } \\
{[\mathrm{mg} / \mathrm{L}]}\end{array}$} & \multicolumn{4}{|c|}{$\begin{array}{c}\text { Lowest CRO Concentration Resulting } \\
\text { in Two-Fold Reduction in } \mathrm{MIC}_{\mathrm{PEN}} \\
\text { or } \mathrm{MIC}_{\mathrm{AMP}}\end{array}$} & \multicolumn{4}{|c|}{$\begin{array}{c}\text { Lowest CRO Concentration Resulting } \\
\text { in Four-Fold Reduction in } \mathrm{MIC}_{\mathrm{PEN}} \\
\text { or } \mathrm{MIC}_{\mathrm{AMP}}\end{array}$} & \multicolumn{4}{|c|}{$\begin{array}{c}\text { Lowest CRO Concentration Resulting } \\
\text { in Eight-Fold Reduction in MIC } \text { PEN } \\
\text { or MIC } \text { AMP }_{\text {A }}\end{array}$} \\
\hline & & \multicolumn{2}{|c|}{ Penicillin } & \multicolumn{2}{|c|}{ Ampicillin } & \multicolumn{2}{|c|}{ Penicillin } & \multicolumn{2}{|c|}{ Ampicillin } & \multicolumn{2}{|c|}{ Penicillin } & \multicolumn{2}{|c|}{ Ampicillin } \\
\hline & & $\begin{array}{l}\text { CRO } \\
\text { conc. } \\
{[\mathrm{mg} / \mathrm{L}]}\end{array}$ & $\mathrm{FICI}^{\mathrm{a}}$ & $\begin{array}{l}\text { CRO } \\
\text { conc. } \\
{[\mathrm{mg} / \mathrm{L}]}\end{array}$ & FICI & $\begin{array}{l}\text { CRO } \\
\text { conc. } \\
{[\mathrm{mg} / \mathrm{L}]}\end{array}$ & FICI & $\begin{array}{l}\text { CRO } \\
\text { conc. } \\
{[\mathrm{mg} / \mathrm{L}]}\end{array}$ & FICI & $\begin{array}{l}\text { CRO } \\
\text { conc. } \\
{[\mathrm{mg} / \mathrm{L}]}\end{array}$ & FICI & $\begin{array}{l}\text { CRO } \\
\text { conc. } \\
{[\mathrm{mg} / \mathrm{L}]}\end{array}$ & FICI \\
\hline 5187 & $1-2$ & 1 & 1.50 & 0.5 & 1.00 & 1 & 1.25 & 0.5 & 0.75 & N.A. & N.A. & 0.5 & 0.625 \\
\hline 245 & 2 & 0.5 & 0.75 & 0.5 & 0.75 & 1 & 0.75 & 0.5 & 0.50 & N.A. & N.A. & 0.5 & 0.375 \\
\hline 26,786 & 2 & 0.25 & 0.625 & 0.5 & 0.75 & 1 & 0.75 & 1 & 0.74 & 1 & 0.625 & N.A. & N.A. \\
\hline 404 & 4 & 1 & 0.75 & 1 & 0.75 & 2 & 0.75 & 1 & 0.49 & N.A. & N.A. & 2 & 0.625 \\
\hline ATCC & 4 & 1 & 0.75 & 0.5 & 0.625 & 2 & 0.75 & 1 & 0.50 & N.A. & N.A. & 2 & 0.625 \\
\hline 6747 & 4 & 1 & 0.75 & 0.5 & 0.625 & 2 & 0.75 & 1 & 0.50 & N.A. & N.A. & 2 & 0.625 \\
\hline 11,223 & 8 & 1 & 0.625 & 1 & 0.625 & 1 & 0.375 & 1 & 0.375 & 4 & 0.625 & 4 & 0.625 \\
\hline 22,424 & 8 & 1 & 0.625 & 1 & 0.625 & 2 & 0.5 & 1 & 0.375 & 4 & 0.625 & 2 & 0.375 \\
\hline 8669 & 8 & 1 & 0.625 & 0.5 & 0.563 & 4 & 0.75 & 1 & 0.375 & N.A. & N.A. & 2 & 0.375 \\
\hline 9367 & 8 & 1 & 0.625 & 0.5 & 0.563 & 2 & 0.50 & $1-2$ & 0.50 & 4 & 0.625 & 2 & 0.375 \\
\hline 1653 & 8 & 1 & 0.625 & 0.5 & 0.563 & $1-2$ & 0.50 & 1 & 0.375 & 4 & 0.625 & $2-4$ & 0.625 \\
\hline 848 & 8 & 1 & 0.625 & $0.5-1$ & 0.625 & 1 & 0.375 & 1 & 0.375 & 4 & 0.625 & 2 & 0.375 \\
\hline 5597 & $8-16$ & 1 & 0.625 & 0.5 & 0.563 & 2 & 0.50 & 2 & 0.25 & 8 & 1.125 & 4 & 0.625 \\
\hline 10,485 & 16 & 1 & 0.56 & 0.25 & 0.52 & 2 & 0.375 & 1 & 0.31 & 4 & 0.375 & 2 & 0.25 \\
\hline 6886 & 16 & 1 & 0.563 & $0.5-1$ & 0.563 & 4 & 0.50 & 1 & 0.313 & 4 & 0.375 & 4 & 0.375 \\
\hline 281 & 16 & $1-2$ & 0.625 & 0.5 & 0.53 & $4-8$ & 0.75 & 1 & 0.313 & 8 & 0.625 & 4 & 0.375 \\
\hline 67,230 & 16 & 1 & 0.563 & $0.5-1$ & 0.563 & 2 & 0.375 & $1-2$ & 0.375 & 4 & 0.375 & 4 & 0.375 \\
\hline 2164 & 16 & 1 & 0.563 & 1 & 0.563 & 2 & 0.375 & $2-4$ & 0.50 & 4 & 0.375 & 8 & 0.625 \\
\hline 4497 & 32 & 1 & 0.53 & 0.5 & 0.563 & $2-4$ & 0.375 & 2 & 0.313 & 8 & 0.375 & 4 & 0.25 \\
\hline 10,021 & 32 & 2 & 0.56 & 0.125 & 0.50 & N.A. & N.A. & 0.5 & 0.266 & N.A. & N.A. & 2 & 0.18 \\
\hline 13,703 & 256 & 1 & 0.50 & 1 & 0.50 & 1 & 0.26 & 1 & 0.25 & 16 & 0.25 & 8 & 0.16 \\
\hline 7914 & 256 & 1 & 0.50 & 1 & 0.50 & 8 & 0.28 & 4 & 0.26 & 64 & 0.375 & 64 & 0.375 \\
\hline 905 & 512 & $2-4$ & 0.51 & 1 & 0.50 & 32 & 0.313 & $4-8$ & 0.266 & N.A. & N.A. & 64 & 0.25 \\
\hline 6037 & 1024 & 8 & 0.51 & 0.5 & 0.50 & 128 & 0.375 & $0.5-1$ & 0.251 & 512 & 0.625 & $2-4$ & 0.13 \\
\hline 7183 & 1024 & 16 & 0.52 & $0.5-1$ & 0.50 & 64 & 0.313 & 64 & 0.313 & 256 & 0.375 & N.A. & N.A. \\
\hline 3043 & $>1024$ & 512 & N.A. & 4 & N.A. & 1024 & N.A. & 128 & N.A. & N.A. & N.A. & N.A. & N.A. \\
\hline 8653 & $>1024$ & 512 & N.A. & 2 & N.A. & N.A. & N.A. & N.A. & N.A. & N.A. & N.A. & N.A. & N.A. \\
\hline 3062 & $>1024$ & 128 & N.A. & $32-64$ & N.A. & $\begin{array}{l}256- \\
512\end{array}$ & N.A. & 256 & N.A. & $\begin{array}{l}512- \\
1024\end{array}$ & N.A. & N.A. & N.A. \\
\hline 9190 & $>1024$ & $64-128$ & N.A. & 2 & N.A. & 512 & N.A. & 256 & N.A. & N.A. & N.A. & N.A. & N.A. \\
\hline
\end{tabular}

a Synergistic FICI values $\leq 0.5$ obtained at free ceftriaxone trough concentrations (CRO conc. $=1$ to $4 \mathrm{mg} / \mathrm{L}$ ) are indicated in bold. Two-, four- and eight-fold reductions in $\mathrm{MIC}_{\mathrm{PEN}}$ or $\mathrm{MIC}_{\mathrm{AMP}}$ correspond to fractional inhibitory concentration $(\mathrm{FIC})$ values $\left(\mathrm{FIC}_{\mathrm{A}}=\mathrm{MIC}_{\mathrm{A}}\right.$ combined $/ \mathrm{MIC}_{\mathrm{A}}$ alone; $\mathrm{FIC}_{\mathrm{A}}+\mathrm{FIC}_{\mathrm{B}}=\mathrm{FICI}_{\mathrm{A} / \mathrm{B}}$ ) of $0.5,0.25$ and 0.125 . The respective FICs of ceftriaxone are calculated by dividing the lowest sub-MIC CRO concentration (CRO conc.) by the $\mathrm{MIC}_{\mathrm{CRO}}$. N.A. = the respective reduction in $\mathrm{MIC}_{\mathrm{PEN}}$ or $\mathrm{MIC}_{\mathrm{AMP}}$ not reached.

\section{Discussion}

The synergy analysis of ampicillin/ceftriaxone and penicillin/ceftriaxone in $29 \mathrm{E}$. faecalis isolates revealed that both combinations have comparable synergistic effects for isolates with $\mathrm{MIC}_{\mathrm{CRO}} \leq 256 \mathrm{mg} / \mathrm{L}$. A reduction in the $\mathrm{MIC}_{\mathrm{PEN}}$ with the addition of ceftriaxone concentrations approximating free ceftriaxone trough concentrations was shown in all of these isolates. In contrast, for isolates with $\mathrm{MIC}_{\mathrm{CRO}} \geq 512 \mathrm{mg} / \mathrm{L}$ discordance was seen 
between the synergy provided by ampicillin/ceftriaxone and by penicillin/ceftriaxone at free ceftriaxone trough concentrations. These ceftriaxone concentrations were insufficient in combination with penicillin, but sufficient in combination with ampicillin to produce a synergistic effect for isolates with an $\mathrm{MIC}_{\mathrm{CRO}} \geq 512 \mathrm{mg} / \mathrm{L}$.

While a synergistic effect between ampicillin and ceftriaxone in $E$. faecalis is not a new finding, and in fact forms part of the basis for recommending this combination for the treatment of EFIE, there are currently no data available showing a potential synergistic effect between penicillin and ceftriaxone. Importantly, our study shows that a similar synergistic effect between penicillin and ceftriaxone cannot be assumed just because there is a proven synergistic effect between ampicillin and ceftriaxone. Although our sample size is relatively small, with 29 E. faecalis isolates, the study on which the current guidelines for the use of ampicillin and ceftriaxone for the treatment of EFIE is based contained just 10 isolates [22]. Our data show that the suitability of penicillin/ceftriaxone for the treatment of EFIE likely depends on the specific isolate's ceftriaxone susceptibility. However, the interpretation of the relationship between ceftriaxone susceptibility and penicillin/ceftriaxone synergy in this study is limited by the lack of isolates with an $\mathrm{MIC}_{\mathrm{CRO}}$ of 64 and $128 \mathrm{mg} / \mathrm{L}$, as well as by the limited number of isolates with an $\mathrm{MIC}_{\mathrm{CRO}}$ of 256 and $512 \mathrm{mg} / \mathrm{L}$. Our $E$. faecalis strain collection comprises 50 clinical isolates collected between 2015 and 2017. The ceftriaxone MIC testing of this collection shows two populations: a larger population of isolates $(68 \%)$ centred around $8 \mathrm{mg} / \mathrm{L} \pm 1-2 \times$ MIC and a smaller population of isolates $(32 \%)$ centered around $512 \mathrm{mg} / \mathrm{L} \pm 1 \times \mathrm{MIC}$ (Figure S1). None of our isolates exhibited a

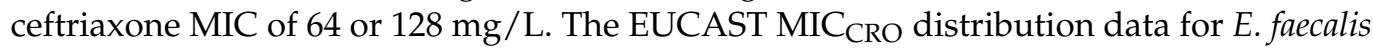
show that, of the 8314 submitted clinical isolates, only $5 \%$ had an $\mathrm{MIC}_{\mathrm{CRO}} \leq 32 \mathrm{mg} / \mathrm{L}$ [23], which contrasts strongly with the $\mathrm{MIC}_{\mathrm{CRO}}$ distribution of our cohort.

Caution should be applied when drawing conclusions from microbiological studies for use in the clinical setting. While the checkerboard assay has been intensively used for studying antibiotic interactions, clinical correlation studies linking in vitro synergy data to direct treatment outcomes are lacking. The methodology of the checkerboard assay does have some limitations, such as a high degree of variability in the selection of the wells used for the final FICI calculation [24,25]. To compensate for a potential selection bias leading to an overestimation of the synergistic effect, we used the median FICI, the lowest FICI, and one-point FICIs at free ceftriaxone trough concentrations for a clinically meaningful interpretation of the checkerboard assay.

The synergistic effect of dual beta-lactam therapy is thought to be based on the complementary inhibition of penicillin binding protein (PBP) homologues, resulting in the inhibition of cell-wall synthesis. Little is known about the detailed functions of PBPs in $E$. faecalis, and this understanding is complicated by the inconsistent labelling of the different PBP homologues [26]. The synergism of amoxicillin/cefotaxime in a single E. faecalis isolate was postulated to be explained by the partial saturation of the essential PBPs 4 and 5 by amoxicillin, coupled with the complete saturation of the non-essential PBPs 2 and 3 by very low cefotaxime concentrations [27]. Ceftriaxone resistance is known to be mediated by the overproduction and mutations of PBPs 4 and 5 as well as other, novel low-affinity class-B PBPs, further reducing the already low affinity of ceftriaxone for these essential PBPs [26]. The discordance of the synergistic effects between ampicillin/ceftriaxone and penicillin/ceftriaxone in isolates with high $\mathrm{MIC}_{\mathrm{CRO}}$ might be explained by the more complete saturation of the ceftriaxone-resistance-mediating PBP profile by ampicillin than by penicillin. The difference in saturation would mean that higher ceftriaxone concentrations would be required to compensate for the poorer binding of penicillin to the altered PBPs. This explanation is supported by the fact that the $\mathrm{MIC}_{\mathrm{PEN}}$, but not the $\mathrm{MIC}_{\mathrm{AMP}}$, positively correlated with the $\mathrm{MIC}_{\mathrm{CRO}}$, indicating that both antibiotics target similar PBP homologues. Interestingly, a study with one E. faecalis isolate showed no interaction between penicillin/ceftriaxone, but synergistic interaction between penicillin/ceftaroline, which is a novel cephalosporin with enhanced affinity to PBP 5 [28]. This further supports the 
hypothesis that the incomplete binding of PBP 5 by penicillin and ceftriaxone counteracts the synergistic effect.

The addition of ceftriaxone to benzylpenicillin provides synergy, or at least partial synergy, for E. faecalis isolates with an $\mathrm{MIC}_{\mathrm{CRO}} \leq 256 \mathrm{mg} / \mathrm{L}$. No significant benefit from adding ceftriaxone to benzylpenicillin is expected for any isolate with an $\mathrm{MIC}_{\mathrm{CRO}} \geq 512 \mathrm{mg} / \mathrm{L}$. These microbiological data support the use of OPAT treatment with the continuous infusion of benzylpenicillin and ceftriaxone for EFIE for isolates with an MIC $_{\mathrm{CRO}} \leq 256 \mathrm{mg} / \mathrm{L}$. As the penicillin/ceftriaxone synergy-testing data for isolates with $\mathrm{MIC}_{\mathrm{CRO}}$ of 64 to $512 \mathrm{mg} / \mathrm{L}$ are limited in this study, further investigation is required to establish a reliable $\mathrm{MIC}_{\mathrm{CRO}}$ cut-off above which the combination of benzylpenicillin and ceftriaxone is not superior to benzylpenicillin alone.

Supplementary Materials: The following are available online at https:/ / www.mdpi.com/article/10 .3390/microorganisms9102150/s1: Figure S1: Ceftriaxone MIC distribution data for the E. faecalis strain collection; Table S1: Antibiotic susceptibility results determined by Vitek 2 (bioMerieux, Craponne, France).

Author Contributions: Conceptualisation, L.T., S.B., and E.D.; methodology, L.T., S.B., and E.D.; validation, L.T., S.B., and E.D.; formal analysis, L.T.; investigation, L.T.; resources, L.T.; data curation, L.T.; writing—original draft preparation, L.T.; writing—review and editing, L.T., S.B., E.D., O.M., and M.W.P.; visualisation, L.T.; supervision, M.W.P.; project administration, L.T.; funding acquisition, O.M., M.W.P. All authors have read and agreed to the published version of the manuscript.

Funding: This work was supported by the Federal Ministry of Education and Research, Germany (grant numbers 01KI1501 and 13N15467).

Institutional Review Board Statement: Not applicable.

Informed Consent Statement: Not applicable.

Data Availability Statement: No further datasets are available.

Acknowledgments: The graphical abstract was created with BioRender.com.

Conflicts of Interest: The authors declare no conflict of interest.

\section{References}

1. Fernández-Hidalgo, N.; Escolà-Vergé, L.; Pericàs, J.M. Enterococcus faecalis endocarditis: What's next? Future Microbiol. 2020, 15, 349-364. [CrossRef]

2. Habib, G.; Lancellotti, P.; Antunes, M.J.; Bongiorni, M.G.; Casalta, J.P.; Del Zotti, F.; Dulgheru, R.; El Khoury, G.; Erba, P.A.; Iung, B.; et al. ESC Guidelines for the management of infective endocarditis: The task force for the management of infective endocarditis of the European Society of Cardiology (ESC). Endorsed by: European Association for Cardio-Thoracic Surgery (EACTS), the European Association of Nuclear Medicine (EANM). Eur. Heart J. 2015, 36, 3075-3128. [PubMed]

3. Baddour, L.M.; Wilson, W.R.; Bayer, A.S.; Fowler, V.G., Jr.; Tleyjeh, I.M.; Rybak, M.J.; Barsic, B.; Lockhart, P.B.; Gewitz, M.H.; Levison, M.E.; et al. Infective endocarditis in adults: Diagnosis, antimicrobial therapy, and management of complications: A scientific statement for healthcare professionals from the american heart association. Circulation 2015, 132, 1435-1486. [CrossRef] [PubMed]

4. $\quad$ El Rafei, A.; DeSimone, D.C.; Narichania, A.D.; Sohail, M.R.; Vikram, H.R.; Li, Z.; Steckelberg, J.M.; Wilson, W.R.; Baddour, L.M. Comparison of Dual $\beta$-Lactam therapy to penicillin-aminoglycoside combination in treatment of Enterococcus faecalis infective endocarditis. J. Infect. 2018, 77, 398-404. [CrossRef] [PubMed]

5. Andrews, M.-M.; von Reyn, C.F. Patient selection criteria and management guidelines for outpatient parenteral antibiotic therapy for native valve infective endocarditis. Clin. Infect. Dis. 2001, 33, 203-209. [CrossRef]

6. Pericà, S.J.M.; Llopis, J.; González-Ramallo, V.; Goenaga, M.Á.; Muñoz, P.; García-Leoni, M.E.; Fariñas, M.C.; Fariñas, M.C.; Ambrosioni, J.; Luque, R.; et al. Outpatient parenteral antibiotic treatment for infective endocarditis: A prospective cohort study from the GAMES cohort. Clin. Infect. Dis. 2019, 69, 1690-1700. [CrossRef] [PubMed]

7. Gil-Navarro, M.V.; Lopez-Cortes, L.E.; Luque-Marquez, R.; Galvez-Acebal, J.; de Alarcon-Gonzalez, A. Outpatient parenteral antimicrobial therapy in Enterococcus faecalis infective endocarditis. J. Clin. Pharm. Ther. 2018, 43, 220-223. [CrossRef]

8. Nakamura, T.; Enoki, Y.; Uno, S.; Uwamino, Y.; Iketani, O.; Hasegawa, N.; Matsumoto, K. Stability of benzylpenicillin potassium and ampicillin in an elastomeric infusion pump. J. Infect. Chemother. 2018, 24, 856-859. [CrossRef] 
9. Tice, A.D.; Rehm, S.J.; Dalovisio, J.R.; Bradley, J.S.; Martinelli, L.P.; Graham, D.R.; Gainer, R.B.; Kunkel, M.J.; Yancey, R.W.; Williams, D.N.; et al. Practice guidelines for outpatient parenteral antimicrobial therapy. Clin. Infect. Dis. 2004, 38, 1651-1671. [CrossRef]

10. Maher, M.; Jensen, K.J.; Lee, D.; E Nix, D. Stability of ampicillin in normal saline and buffered normal saline. Int. J. Pharm. Compd. 2016, 20, 338-342.

11. Huskey, M.; Lewis, P.; Brown, S.D. Stability of ampicillin in normal saline following refrigerated storage and 24-hour pump recirculation. Hosp. Pharm. 2020. [CrossRef]

12. Iversen, K.; Ihlemann, N.; Gill, S.U.; Madsen, T.; Elming, H.; Jensen, K.T.; Bruun, N.E.; Høfsten, D.E.; Fursted, K.; Christensen, J.J.; et al. Partial oral versus intravenous antibiotic treatment of endocarditis. N. Engl. J. Med. 2019, 380, 415-424. [CrossRef] [PubMed]

13. Suzuki, H.; Carlson, J.R.; Matsumoto, E. Treatment of enterococcus faecalis infective endocarditis with penicillin $G$ plus ceftriaxone. J. Infect. Dis. 2020, 52, 135-138. [CrossRef]

14. Tritle, B.J.; Timbrook, T.T.; Fisher, M.A.; Spivak, E.S. Penicillin as a potential agent for dual $\beta$-lactam therapy for enterococcal endocarditis. Clin Infect Dis. 2020, 70, 1263-1264. [CrossRef] [PubMed]

15. Briggs, S.; Broom, M.; Duffy, E.; Everts, R.; Everts, G.; Lowe, B.; McBride, S.; Bhally, H. Outpatient continuous-infusion benzylpenicillin combined with either gentamicin or ceftriaxone for enterococcal endocarditis. J. Antimicrob. Chemother. 2021. [CrossRef] [PubMed]

16. EUCAST. EUCAST Reading Guide for Broth Microdilution, Version 3.0 January 2021. Available online: https://www.eucast.org/ ast_of_bacteria/mic_determination/?no_cache=1 (accessed on 5 March 2021).

17. Stein, C.; Makarewicz, O.; Bohnert, J.A.; Pfeifer, Y.; Kesselmeier, M.; Hagel, S.; Pletz, M.W. Three dimensional checkerboard synergy analysis of colistin, meropenem, tigecycline against multidrug-resistant clinical klebsiella pneumonia isolates. PLoS ONE 2015, 10, e0126479. [CrossRef]

18. Herrera-Hidalgo, L.; de Alarcón, A.; López-Cortes, L.E.; Luque-Márquez, R.; López-Cortes, L.F.; Gutiérrez-Valencia, A.; GilNavarro, M.V. Is once-daily high-dose ceftriaxone plus ampicillin an alternative for enterococcus faecalis infective endocarditis in outpatient parenteral antibiotic therapy programs? Antimicrob. Agents Chemother. 2020, 65, e02099-20. [CrossRef] [PubMed]

19. Patel, I.H.; Chen, S.; Parsonnet, M.; Hackman, M.R.; A Brooks, M.; Konikoff, J.; A Kaplan, S. Pharmacokinetics of ceftriaxone in humans. Antimicrob. Agents Chemother. 1981, 20, 634-641. [CrossRef] [PubMed]

20. Pollock, A.A.; Tee, P.E.; Patel, I.H.; Spicehandler, J.; Simberkoff, M.S.; Rahal, J.J. Pharmacokinetic characteristics of intravenous ceftriaxone in normal adults. Antimicrob. Agents Chemother. 1982, 22, 816-823. [CrossRef]

21. Thieme, L.; Klinger-Strobel, M.; Hartung, A.; Stein, C.; Makarewicz, O.; Pletz, M.W. In vitro synergism and anti-biofilm activity of ampicillin, gentamicin, ceftaroline and ceftriaxone against Enterococcus faecalis. J. Antimicrob. Chemother. 2018, 73, $1553-1561$. [CrossRef]

22. Gavaldà, J.; Torres, C.; Tenorio, C.; López, P.; Zaragoza, M.; Capdevila, J.A.; Almirante, B.; Ruiz, F.; Borrell, N.; Gomis, X.; et al. Efficacy of ampicillin plus ceftriaxone in treatment of experimental endocarditis due to enterococcus faecalis strains highly resistant to aminoglycosides. Antimicrob. Agents Chemother. 1999, 43, 639-646. [CrossRef] [PubMed]

23. EUCAST. EUCAST MIC Distributions for Ceftriaxone. Available online: https://mic.eucast.org/search/?search\%5Bmethod\% 5D=mic\&search $\% 5$ Bantibiotic $\% 5 \mathrm{D}=57 \&$ search $\% 5$ Bspecies $\% 5 \mathrm{D}=-1 \&$ search $\% 5$ Bdisk_content $\% 5 \mathrm{D}=-1 \&$ search $\% 5 \mathrm{Blimit} \% 5 \mathrm{D}=50$ (accessed on 5 March 2021).

24. Odds, F.C. Synergy, antagonism, and what the chequerboard puts between them. J. Antimicrob. Chemother. 2003, 52, 1. [CrossRef] [PubMed]

25. Bonapace, C.R.; Bosso, J.A.; Friedrich, L.V.; White, R.L. Comparison of methods of interpretation of checkerboard synergy testing. Diagn. Microbiol. Infect. Dis. 2002, 44, 363-366. [CrossRef]

26. Djorić, D.; Little, J.L.; Kristich, C.J. Multiple low-reactivity class b penicillin-binding proteins are required for cephalosporin resistance in enterococci. Antimicrob. Agents Chemother. 2020, 64. [CrossRef]

27. Mainardi, J.L.; Gutmann, L.; Acar, J.F.; Goldstein, F.W. Synergistic effect of amoxicillin and cefotaxime against Enterococcus faecalis. Antimicrob. Agents Chemother. 1995, 39, 1984-1987. [CrossRef] [PubMed]

28. Cusumano, J.; Daffinee, K.; Bodo, E.; Laplante, K. Alternative Dual Beta-Lactam Combinations for Enterococcus Faecalis Infective Endocarditis; abstract P2804; ECCMID: Amsterdam, The Netherlands, 2019. 